\title{
The acquisition of onset Consonant Clusters by Persian Speakers (L1), Learners of English (L2) and French (L3): An optimality Account
}

\author{
Ali Akbar Jabbari ${ }^{\mathrm{a}}$, Fateme Pourmajnoun ${ }^{\mathrm{b}}$ \\ a Associate professor of Applied Linguistics, Yazd University, Yazd, Iranb MA in TEFL, Yazd University, Yazd, \\ Iran
}

\begin{abstract}
This study accounts for the acquisition of onset consonant clusters of French by Persian EFL learners. In Persian onset consonant structure is " $\mathrm{CV}$ ", composed of one obligatory consonant and an obligatory vowel. In English the initial syllable structure is "(CCC) V", composed of three optional consonants and an obligatory vowel. The initial syllable structure in French is like English initial syllable. Therefore, Persian EFL learners may transfer the structures that they have acquired in Persian and English into French. This study investigates four hypotheses of transfer, L1 Transfer Hypothesis, L2 Status Factor, Cumulative Enhancement Model and Typological Primacy Model. Optimality Theory claims that the knowledge of languages is based on a set of constraints that are universal and ranked differently depending on a given language. This theory provides an explicit account why learners have difficulty with specific third language syllable structures and how they resolve it. Forty two participants of two levels of pre and upper-intermediate of English proficiency and beginner level French proficiency were selected. The data were collected through a comprehension and a production task. It was found that the participants had difficulties in performing initial consonant clusters in French; however, the lower level learners in English proficiency had more difficulties so learners transfer both structures from L1 and L2 into L3.
\end{abstract}

KEYWORDS: Onset Consonant Cluster, Optimality Theory, Transfer

\section{INTRODUCTION}

Multilingualism is a very broad phenomenon in today's society as many people travel around the world, immigrate to other countries or trade with no difficulty. Multingual acquisition is more complex than second language acquisition because it implicates all the factors and processes associated with second language acquisition as well as unique and potentially more complex factors and effects associated with the interactions that can take place among the multiple languages being learned, i.e. previously learned languages, and the processes and effects of learning them.

Multilingualism has long been of interest to researchers but most of the researches have explored the topic sociolinguistically (e.g., Weinreich 1953; Vildomec 1963) and few studies have been carried out on the phonological aspect. The onset syllable structure in the three languages of Persian (the participants' L1), English (L2), and French (L3) has been considered at the main aspect under investigation. The permitted initial consonant clusters in French and English are (ccv) and (cccv) respectively; however, Persian does not allow such structures (L1\#L2=L3).

The present study is conducted to fill the gap in the literature by exploring the extent to which L1 (Persian) and L2 (English) can have influence on learning L3 (French), and finding the main source of transfer to L3 (French). Furthermore, it is aimed at exploring whether the results of the study can provide support for the following key concepts in L3 acquisition namely, L1 transfer, L2 status Factor, Cumulative Enhancement Model (CEM), Typological Primacy Model, and the proficiency level. In this study, Optimality Theory has been applied to explain why Persian learners of French with English background make mistakes in their correct pronunciation of onset syllable structure.Last but not the least, the study attempts to explain the reason why Persian learners of French with English background make pronunciation mistakes in onset syllable structure on the basis of Optimality Theory and various possible rankings of its universal constraints. It is presumed that OT can reveal the major sources of difficulties faced by L1 Persian learners.

The study, thus, seeks to find the answers for the following research questions:

1) Does the combination of previously learned onset syllable structure of L1 and L2 have an effect on learning L3 French?

2) Does the learners' English proficiency level play significant role in the acquisition of French onset syllable structure? 
3) How can Optimality Theory account for the acquisition of French onset syllable structure by L1 Persian, L2 English, and L3 French learners?

In what follows, Section 2 reviews the relevant literature in the field of multilingualism and third language acquisition and Optimality theory. Section 3 offers a detailed account of the research participants, data collection instruments and data analysis methods. Next, a brief overview of the variables and coding procedures is given. Finally, Section 5 responds the research questions posed at the beginning of the study and explains the results.

\section{REVIEW OF LITRETURE}

Over the past few decades, there has been a marked increase in the field of multilingualism and consequently, several scholars have attempted to investigate the multilingual behavior. The works conducted on sociolinguistic and educational aspects of multilingualism (Abu-Rabia, 1998; Bhatia, 2004; Bild \& Swain, 1989; Brohy, 2001; Cenoz et al., 2001; Cummins, 2001; Dagenais \& Day, 1998; Edwards, 1994; Kramsch, 2006; Oksaar, 1983; Pandey, 1991) provide support for such an interest. However, research on the cognitive and psycholinguistic aspects of multilingualism began to be investigated somehow later in the 1980s, leading scholars to believe that multilingual speakers should not be compared to L2 learners without enough care and caution.

\subsection{Theories Dealing with Transfer in L3 Acquisition}

Central to the discipline of Third Language Acquisition (TLA) is the impact of previously-acquired linguistic knowledge on the process of L3 acquisition. Is L1 the only possible source of transfer in L3 transfer (Leung, 2006), or is the chronologically last system acquired (the L2) the main source (Bardel and Falk, 2007), or can transfer come from either system (Flynn et al., 2004). These are among the questions that have recently grown in importance.

Williams and Hammarberg (1998) referred to the process of L2 activation in L3 use as 'the L2 status factor'. According to L2 status factor, learners have a tendency to activate a previously acquired second language when producing in an L3. They further highlighted additional factors that might be at play in crosslinguistic influences at a lexical level which are 'recency' and 'proficiency'.

Soon afterwards, several other studies provided evidence that the second language (L2) is one source of transfer in L3 acquisition especially when it comes to syntax (Flynn et al., 2004; Leung, 2005), and some studies even claimed that L2 play a more significant role compared to the first language (L1) in L3 syntax in the initial state (Bardel \& Falk, 2007; Rothman \& Cabrelli Amaro, 2010).

In the study of Bardel and Falk (2007), transfer was shown to be dependent on the degree of typological correspondence between L2 and L3. The findings argued against the L1 transfer hypothesis in L3 acquisition, and provided ample support for the L2 status factor hypothesis and concluded that the 'L2 status factor' is the stronger predictor of initial transfer in L3. It was suggested that L2 plays an impeding role in the occurrence of L1 transfer even if it would lead to target-like L3 production.

In a much similar vein, Bardel and Falk's (2011) findings lend support to the claim that non-native languages differ cognitively from first languages and will consequently be favored as transfer source in case of L3 acquisition. A formally learned L2 and L3 have many cognitive and situational similarities. The reason why L1 is not considered as transfer source is that L1 does not share many of these features.

Cumulative Enhancement model (CEM) was later proposed by Flynn et al. (2004) and yielded inconsistent results with Bardel and Falk's (2011) data. Flynn et al. (2004) argued that any previously acquired language either has a scaffolding effect in the sense that any prior language can either enhance subsequent language acquisition or remains neutral. According to CEM, both L1 and L2 may be sources of transfer; however, the L2 takes precedence over L1 only in cases when the TL form is not present in the L1. In other words, all the previously learned languages can be beneficial in the acquisition of the L3.

Similar to CEM, the Typological Primacy Model (TPM), which originates from Rothman and Cabrelli Amaro's (2010) work, anticipates that either the L1 or the L2 morphosyntactic features can transfer in L3 acquisition and the transfer may come from either of the previously-acquired languages. In other words, neither of the prior languages has an added chance of being transferred when it comes to L3 functional categories. Unlike the CEM, the TPM anticipates that transfer is selective depending on either actual typological proximity or psychotypology. By psychotypology, Rothman (2010) refers to a speaker's perceived typological closeness between the three languages. TPM hypothesizes that the relative typological proximity of the systems is assessed and the system which should be transferred is selected accordingly.

\subsection{The factors Conditioning L3 Acquisition}

The level of proficiency is commonly referred to as one of the determining factor conditioning transfer and includes level of proficiency in the target language as well as in the background languages (Dewaele, 2001; 
Bardel \& Lindqvist, 2007). Regarding the interrelationship between proficiency level and transfer of linguistic items, several studies have demonstrated that transfer at the level of lexical items mostly happens when the learner has a low level of proficiency. On the contrary, for syntactic categories to be transferred, learners must have reached a certain level of development in the L2 (Bardel \& Falk, 2007; Rothman \& Cabrelli Amaro, 2010). The positive correlation between the level of proficiency in the L2 on the one hand and the degree of achievement in the L3 acquisition and the rate of transfer of language structures from the L2 into L3 on the other hand has been suggested by De Angelis (2007). According to Williams and Hammarberg (1998), if learners have a higher level of proficiency in another language, it may contribute differently to the subsequent acquisition of a new language compared to the native language. In another study by Bardel and Falk (2010), it was discussed that the L2 and the L3 proficiency level can affect the activation of previously acquired languages. Bardel and Falk (2007) also suggested that the learners have to be proficient in the L2 so that they can transfer structures from L2 into L3.

Two additional factors that are under investigation in L3 research are typology and psychotypology: Croft (1990) mentioned the term typology to denote the similarity between linguistic features, for example the verb-final property that applies to the non-related languages German and Turkish. Psychotypology, on the other hand, was coined by Kellerman (1983) to refer to the learner's perception of the linguistic similarities among languages.

The idea of recency is another issue that might be at work and refer to "how recently a language was last used" (De Angelis 2007, p. 35), and "to the degree of recent contact with a certain background language" (Falk \& Bardel 2010). Based on the notion of recency, it is believed that the most recently used language will have priority over others and will be activated at a greater pace. William and Hammarberg (1998) regarded the notion of 'recency as one of the four elements which would play a significant role in the production process of the target language.

\subsection{Optimality Theory (OT)}

OT hypothesizes that the output forms of language stem from the interaction among the conflicting constraints. According to OT, the inputs are considered as the underlying representations, and the outputs as their surface realizations. In what follows, the three key notions and fundamental components of OT as proposed by Prince and Smolensky (1993) are provided:

a) Gen (generator) generates the list of possible outputs, or candidates from an input. The list of possible outputs created by Gen for a given input is called the candidate set. The relationship among the input, Gen, and the candidate set is presented graphically below.

b) Con (constraints) provides a set of strictly ordered violable constraints and criteria to decide between candidates.

c) Eval (evaluator) Gen produces a candidate set from an input, and that candidate set is submitted to the Evaluator. Eval's main function is to decide on the optimal candidate. It chooses the optimal candidate based on the constraints, and this candidate is the output. Eval does this by applying a language-particular constraint hierarchy to the set of candidates.

\subsection{Participants}

III. METHOD

To accomplish the main objectives of the study, 42 EFL learners majoring in English Literature at the BA level in Yazd University were selected to take part. The participants were selected through two kinds of Oxford Quick Placement Tests which were administered prior to the study. They were chosen from both male and female students, aged from 18 to 25 . Then, on the basis of the results obtained from the above mentioned placement tests, they were divided into two groups of upper and lower-intermediate which included 20 and 22 participants respectively.

\subsection{Instrumentation}

The instruments that were used to obtain the required information for the present study were comprised of the English and French Oxford Quick Placement Tests to measure the proficiency level of the participants in both English (L2) and French (L3), the Oral Judgment Test (OJT), and the Production Test (PT) to inspect the impact of the prior languages on the acquisition of initial consonant clusters.

\subsubsection{The Production Test (PT)}

Another instrument central to the conduction of the present study was the Production Task (Appendix A) which was programmed so as to observe the performance of the two groups of learners regarding the production of French initial consonant clusters. First, 30 cards were prepared, each one containing one French word. Twenty of the words began with the consonant clusters under investigation and the rest of them were considered as distractors. Then, the instruction was given to them in their mother tongue. The subjects were 
asked to read them out. Their voices were recorded by a high quality recorder and the subjects' pronunciations were recorded and transcribed by two Judges in order to achieve reliable judgment. The time for performing this task for each participant was approximately 6 minutes. The study revolved around four main coda clusters, namely $/ \mathrm{Jt} /, / \mathrm{kt} /, / \mathrm{sm} /$, and $/ \mathrm{bl} /$. The following table illustrates the distribution of the above-mentioned clusters in the Production Test.

\subsubsection{The Oral Judgment Test (OJT)}

The test consisted of 30 items out of which ten items contained two consonant onset clusters (bl/kr) and ten items three consonant onset clusters (str/spr). To mislead the participants regarding the main objectives of the study, ten items were designed as distractors with no consonant onset clusters. The OJT (Appendix B) was administered in an English language laboratory (a sound-attenuated room) with the intention of checking learners' perception of the clusters. The learners were asked to judge and determine the existent and nonexistent pronunciations of onset consonant cluster in French. The subjects were required to listen to a phonetically trained French speaker pronouncing each word twice and then circling one of the alternatives based on their own perception. The maximum response time for each stimulus item was about 5 seconds. They were required to wear headphones to increase their concentration and to remove the interference of the extraneous factors. They listened to 30 pre-recorded words and saw their written pronunciation simultaneously on a paper. The phonetic transcription of each word was presented in multiple choice format with one option as the correct option and three of them as distractors.

\section{RESULTS}

The process of analyzing the data involved a number of quantitative methods of analyses such as twoway between-groups analysis of variance and independent samples t-test along with their associated tables and graphs. The data obtained from the two main tests, i.e. the OJT and the PT, were fed into the SPSS software version 16 for detailed statistical analyses. After checking for the assumptions underlying the ANOVA statistical analysis, a two way ANOVA was conducted to investigate the effects of two independent categorical variables of test type and proficiency level on learners' performance.

As mentioned earlier, the learners' performance on the Production test was recorded by a high quality recorder and their pronunciations were further transcribed by two Judges in order to achieve reliable judgment. Most of the learners adapted two strategies, namely prosthesis and epenthesis, in the pronunciation of the French words which meant that the transfer stemmed from their first language. In order to see if OT can accounts for the results, learners' output forms were checked against what OT had already predicted. The finding of the study revealed that the learners' outputs conformed to the predicted OT tableaux.

\subsection{The Interaction Effect between Task Types and Proficiency Level}

A two-way between-groups analysis of variance was conducted to explore the simultaneous impact of proficiency level and task types on learners' performance. As it can be found from Table 1, the interaction effect between task types and proficiency level was not statistically significant, $F(3,76)=.178, p=.674)$. It indicated that there was no significant difference in the effect of proficiency level on learners' performance in both comprehension and production tasks. However, the main effect of the proficiency level with $F(3,76)=46.212$, $\mathrm{p}=.000$ revealed that the proficiency level could affect the learners' scores. Moreover, the partial eta squared value which was also presented in the table suggested a large effect size (.378). There was also a statistically significant main effect for task types, $\mathrm{F}(3,76)=31.013, \mathrm{p}=.000$ with a large effect size (partial eta squared $=$ $.290)$.

Table 1. Tests of Between-Subjects Effects

\begin{tabular}{|l|r|r|r|r|r|r|}
\hline Source & $\begin{array}{c}\text { Type III } \\
\text { Sum of } \\
\text { Squares }\end{array}$ & \multicolumn{1}{c|}{ df } & \multicolumn{1}{c|}{$\begin{array}{c}\text { Mean } \\
\text { Square }\end{array}$} & \multicolumn{1}{c|}{ F } & \multicolumn{1}{c|}{ Sig. } & $\begin{array}{c}\text { Partial Eta } \\
\text { Squared }\end{array}$ \\
\hline Corrected Model & $655.937^{\mathrm{a}}$ & 3 & 218.646 & 25.801 & .000 & .505 \\
\hline Intercept & 3795.012 & 1 & 3795.012 & 447.824 & .000 & .855 \\
\hline En_proficiency & 391.612 & 1 & 391.612 & 46.212 & .000 & .378 \\
\hline Task_type & 262.812 & 1 & 262.812 & 31.013 & .000 & .290 \\
\hline $\begin{array}{l}\text { En_proficiency } * \\
\text { Task_type }\end{array}$ & 1.513 & 1 & 1.513 & .178 & .674 & .002 \\
\hline Error & 644.050 & 76 & 8.474 & & & \\
\hline Total & 5095.000 & 80 & & & & \\
\hline Corrected Total & 1299.987 & 79 & & & & \\
\hline
\end{tabular}




\subsection{The Hierarchy of Constraints}

As mentioned before, Persian syllabus structure is cvcc and has obligatory onset; therefore, onset condition constraint should be ranked at the highest position. On the other hand it can be inferred that Complex Onset constraint is important as well, then it can be said that this constraint is located exactly after Onset Condition constraint. So far we understand that the violation of these two constraints is seriously prohibited. On the other hand, English is a language that has optional syllable onset and complex onset is also allowed in this language. As a result these two constraints should not be ranked high. Other related constraints are MAX IO, DEP IO and IDENT respectively. Therefore the ranking hierarchy for Persian and English are as follows:

Persian: Onset Condition >>Complex Onset>> MAX IO, DEP IO, IDENT

English: MAX IO, DEP IO > Onset Condition, Complex Onset > IDENT

Since English has complex onset, and speakers of English produce it perfectly, it can be inferred that the faithfulness constraints should be ranked higher.

\section{Epenthesis Rule (DEP-IO)}

Prothesis, the insertion of a vowel before a cluster, is one of the strategies that is applied to break up clusters. In Persian, prothesis happens in SC clusters (e.g. an input or target form 'snober', is adapted as [esnober]).

As discussed before, in OT there is a constraint, DEP-IO that militates against inserting a vowel, which makes the outputs differ from inputs. In Persian this kind of constraint, is a higher-ranked constraint that is triggered by the desire to avoid onset clusters. There is a family of DEP-IO constraints that can be translated to a scale (Fleischhaker, 2001). The general format of this family of constraints is discussed below that can be ranked on a universal ranking scale (Jabbari, 2012).

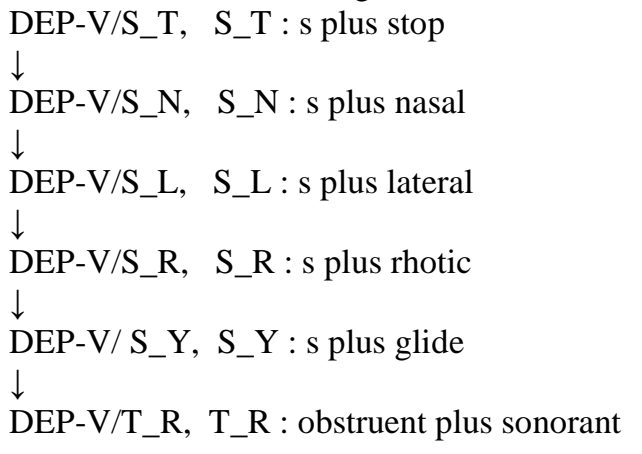

stop, stay, speak, spend, stand 5 ST

snober, snow, slide, smoke, slow 5

tragedy, claim, block, plan, drop 5

SR

TR

\section{COMPLEX (ONSET) (*COMONS)}

This constraint prevents any consonant cluster in the output. ("No onset clusters"). One way to satisfy this constraint would be to delete an onset consonant but Persian learners choose another option, they insert a vowel into or before consonant cluster. We assume the constraint in following is also never violated in Persian:

\section{MAX-IO (ONSET) (MAXONS)}

This constraint assigns a violation mark for any onset segment in the input which does not correspond to an onset segment in the output. ("No deletion in the onset"). It is assumed that this constraint never being violated in Persian.

$\mathbf{C} / \mathbf{V}$ : A consonant must be prevocalic

This constraint must be ranked lower than the constraint against epenthesis into /s/ plus stop and /s/ plus /1/ (or $/ \mathrm{n} /$ ) clusters, because in the outputs for such forms the $\mathrm{C} / \mathrm{V}$ constraint is violated. Let us review the constraints involved in Farsi vowel epenthesis. In Farsi, the constraint

COMPLEX (ONSET) is never violated on the surface. It is also not possible to delete onset consonants, which would be a violation of MAX- ONSET. Both constraints are therefore undominated in the grammar. Epenthesis into SR- and TR- clusters is allowed but not into other types of clusters (s plus stop, s plus nasal, s plus l). We adduced the constraint $\mathrm{C} / \mathrm{V}$ in order to make this difference. This leads to the following constraint hierarchy for Farsi:

*COMPLEX, MAX-IO (ONSET)

|

DEP-V/S_T $\gg D E P-V / S \_N ~ » D E P-V / S \_L ~ » C / V$

| 
DEP-V/S_R »DEP-V/S_Y »DEP-V/T_R

Let us illustrate this ranking on the basis of some of the words that we have seen so far:

COMP $>$ MAX-ONS $>>$ DEPV/S_T $>>$ DEPV/S_N $>$ DEPV/S_L $>$ DEPV/S_L $>$ CV $\gg>$ DEPV/S_R $>$ DEPV/S_Y > DEPV/T_R

\subsection{Input Evaluation}

\section{Evaluation of "blanche"}

Table 2 indicates that the input "blanche" has generated five candidates. The tableau demonstrates the prevailing hierarchy of constraints in Persian that was discussed earlier. The first candidate is fatal since it violates the Complex (Onset) constraint that rules out any consonant cluster in the output. The output "eblanche" is also fatal as it violates one of the high ranking constraints, i.e. C/V. The last two options (lanche and ebanche) violate the second constraint, MAX-IO (Onset), according to which any segment in the input must correspond to an onset segment in the output. Therefore, these two forms are considered fatal as well. The second output "belanche" satisfies all other constraints except DEP-V/T_R which prevents inserting a vowel into the obstruent plus sonorant clusters. Since this constraint has the lowest rank, "belanche" is selected as the optimal form.

Table 2. Evaluation of "blanche"

\begin{tabular}{|c|c|c|c|c|c|c|c|c|c|}
\hline $\begin{array}{l}\frac{\Xi}{0} \\
\frac{\Xi}{\oplus}\end{array}$ & $\underset{\text { ¿্ }}{\stackrel{0}{0}}$ & $\begin{array}{l}\tilde{z} \\
z \\
\dot{1} \\
\dot{x} \\
\Sigma\end{array}$ & 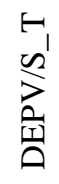 & $\begin{array}{l}z_{1} \\
n^{\prime} \\
\lambda_{0} \\
\text { a d }\end{array}$ & $\begin{array}{l}\overrightarrow{1} \\
\frac{2}{2} \\
\frac{0}{0}\end{array}$ & z & $\begin{array}{l}\simeq 1 \\
\frac{1}{2} \\
\frac{2}{2} \\
\text { In }\end{array}$ & $\begin{array}{l}\lambda_{1} \\
\tilde{D}^{2} \\
\frac{2}{2} \\
\frac{1}{0}\end{array}$ & $\begin{array}{l}a_{1} \\
\frac{5}{2} \\
\frac{1}{1} \\
0\end{array}$ \\
\hline blanche & $* !$ & & & & & $*$ & & & \\
\hline >belanche & & & & & & & & & $*$ \\
\hline eblanche & & & & & & $* !$ & & & \\
\hline lanche & & $* !$ & & & & & & & \\
\hline ebanche & & $* !$ & & & & & & & \\
\hline
\end{tabular}

Evaluation of "spectre"

Table 3 shows the input spectre. The high-ranked MAX-ONS constraint is violated by the candidates pektr and epektr, so these options are fatal. The candidate spectr is also fatal since it violates the high-ranked constraint COMP. Hence, the option espektr is selected as the optimal one. One important point about this input is that, this tableau shows the influence of the constraint against inserting vowels into a $s$ plus stop cluster, DEPV/S_T. Since this constraint is higher-ranked than the constraint $\mathrm{C} / \mathrm{V}$, the form [sepektr] is comparatively worse-formed than [esport]. The latter candidate therefore is optimal output, inspite of its $\mathrm{C} / \mathrm{V}$ violation.

Table 3. Evaluation of "spectre"

\begin{tabular}{|c|c|c|c|c|c|c|c|c|c|}
\hline $\begin{array}{l}\stackrel{0}{0} \\
\text { कू } \\
\text { की }\end{array}$ & $\underbrace{0}_{*}$ & $\begin{array}{l}\tilde{2} \\
\mathbf{0} \\
\dot{x} \\
\dot{x} \\
\Sigma\end{array}$ & $\begin{array}{l}-1 \\
\frac{1}{2} \\
\frac{1}{2} \\
\frac{1}{0}\end{array}$ & $\begin{array}{l}z_{1} \\
n^{\prime} \\
\lambda_{0} \\
\overrightarrow{1} \\
0\end{array}$ & $\begin{array}{l}\overrightarrow{1} \\
\frac{1}{2} \\
\frac{1}{0} \\
\frac{11}{0}\end{array}$ & 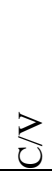 & $\begin{array}{l}\simeq 1 \\
\sqrt{2} \\
\frac{2}{2} \\
\frac{1}{0}\end{array}$ & $\begin{array}{l}\lambda_{1} \\
\frac{\sqrt{2}}{2} \\
\frac{\partial}{0} \\
0\end{array}$ & $\begin{array}{l}x_{1} \\
\frac{5}{2} \\
\frac{2}{1} \\
0\end{array}$ \\
\hline Spectr & $* !$ & & & & & $*$ & & & \\
\hline Sepektr & & & $* !$ & & & & & & * \\
\hline >Espektr & & & & & & $*$ & & & \\
\hline Pektr & & $* !$ & & & & & & & \\
\hline epektr & & $* !$ & & & & & & & \\
\hline
\end{tabular}

\section{DISCUSSION AND CONCLUSION}

The aim of this study was to investigate four hypotheses of transfer in third language acquisition, i.e. L1 transfer hypothesis, L2 status Factor, CEM, and TPM with the aim of clarifying which of these hypotheses of transfer was supported or rejected in acquiring third language and finding out the main source of transfer in L3 acquisition. The role of proficiency in L2 was also taken into consideration. Moreover, Optimality Theory was adapted so that it might provide proper account to transfer phenomenon in L3 acquisition. The present study provides enough evidence against both L1 Transfer Hypothesis and L2 Status Factor as the only source of transfer for multilingual learners and appears to validate a combination of them. Such view rests on the output forms which are believed to show the interference of both the L1 and L2. 
Upon closer inspection of the output forms, it becomes evident that there are numerous examples which distinctly show the effect of the L1 Persian on the production of these forms. Persian and French approach the initial consonant clusters quite differently. While Persian clusters necessitate one obligatory consonant, the existence of consonant in English and French initial clusters is optional. Due to this underlying difference, L3 learners showed a general inclination toward the insertion of a consonant at the beginning of syllables which is in accordance to their L1. Therefore, it can be assumed that the L2, by itself, is not also regarded as the only transfer source.Although the study offers ample support for most of the CEM arguments, it is not totally supported. The notion of the scaffolding effect of previously-acquired languages is rejected. The prior languages do not always enhance subsequent acquisitions or remain neutral as CEM predicts. On the contrary, it is possible that they lead to the production of non native-like forms.

These results provide confirmatory evidence in support of Rothman's Typological Primacy Model (TPM). TPM predicts that the psychotypology determines whether the L1 or L2 will be transferred in L3 acquisition. In other words, the learners' perception concerning the proximity of the two languages is the most crucial factor on the acquisition of the third language. Therefore, either the L1 or the L2 properties can be transferred based on their psychotypological closeness with the possibility that it might lead to the nonfacilitative transfer. It is fairly uncontroversial to consider TPM as the theory which perfectly accounts for the results of the present study because of the existence of non native-like forms in the learners' outputs. Transfer from the L1 or L2 was not proved to be facilitative all the time. Learners in both levels of proficiency made some pronunciation mistakes which were rooted in the transfer from prior languages.

There are several justifications worth highlighting for the outperformance of the upper-intermediate learners. The primary factor that has to be taken into account is the level of proficiency in the source languages. The present study was primarily grounded on the argument that if the learners with advanced levels of proficiency in L2 would be able to produce and comprehend the onset consonant clusters in French, it shows that the L2 is their source of transfer because all the learners are selected with the beginner level of French proficiency, and it means that they have not acquired the L3 onset consonant clusters yet. Therefore, it can be concluded that due to the similarity between L2 and L3, the learners have transfer the onset syllable structure from their L2. On the other hand, if the learners with low level of proficiency in their L2 are not able to produce and comprehend the onset syllabus structure in their L3, the transfer will occur from the L1 to L3. The upperintermediate learners with their background in English performed significantly better than the lowerintermediate ones in both comprehension and production tasks.

Probably, the most obvious justification for the more satisfactory performance of the upper-intermediate learners is the resemblance of L2 English and L3 French with respect to the initial consonant clusters. Although it seems difficult to put a distinction between typology and psychotypology in the practical sense, there is overwhelming evidence to support the ideas that the linguistic similarity among the languages is one of the contributing factors in learning. Due to the similarity or the learners' perception of the closeness of initial consonant clusters in English and French, learners in higher proficiency in L2 transferred the clusters from the L2.

Acknowledging that the general implications from a single study have to be drawn cautiously, there exist certain pedagogical implications based on the results of the present study. The findings of the present study may have major implications for language learners, EFL instructors, teacher trainers, syllabus designers, and materials developers since they are mostly concerned with language at the level of phonology.

Although it is believed that the current study lends some insight into the Persian learners' problems in the acquisition of French onset syllable structure as their third language, there are still some suggestions to extend the domain of research in this area. First of all, the present study was exclusively carried out on the learners' ability in recognition and production of syllabic structure in the individual French words. Further extensive and in-depth investigations into the role of syllabic structure in the connected speech is called for to increase the validity and transferability of the results and to determine the extent to which the results can be generalized to other language components.In addition, this study includes the effect of proficiency level in L2 on the production and perception of French onset syllable structure; therefore, more studies are needed to be conducted on the effect of proficiency level in L3 on the production and perception of onset consonant clusters in French.

\section{REFERENCES}

[1] Abu-Rabia, S. (1998). Reading Arabic texts: Effects of text type, reader type and vowelization. Reading and Writing: An Interdisciplinary Journal, 10, 105-119.

[2] Bardel, C., \& Falk, Y. (2007). The role of the second language in third language acquisition: The case of Germanic syntax. Second Language Research, 23 (4), 459-484.

[3] Bardel, C., \& Falk, Y. (2010). The study of the role of the background languages in third language acquisition. The state of the art. IRAL-International Review of Applied Linguistics in Language Teaching, 48(2-3), 185-219. 
[4] Bardel, C., \& Falk, Y. (2011). Object pronouns in German L3 syntax: Evidence for the L2 status factor. Second Language Research, 27(1), 59-82.

[5] Bardel, C., \& Lindqvist, C. (2007). The role proficiency and psychotypology in lexical cross-linguistic influence. A study of a multilingual learner of Italian L3. In M. Chini, P. Desideri, M. E. Favilla \& G. Pallotti (Eds.), Atti del VI Congresso di Studi dell'Associazione Italiana di Linguistica Applicata, (pp. 123-145). Perugia: Guerra Editore.

[6] Bhatia, V. K., (2004). Worlds of written discourse: A genre-based view. London: Continuum International.

[7] Bild, E.R., \& Swain, M. (1989). Minority language students in a French immersion programme: Their French proficiency. Journal of Multilingual and Multicultural Development , 10, 255-274.

[8] Brohy, C. (2001). Generic and/or specific advantages of bilingualism in a dynamic plurilingual situation: The case of French as official L3 in the school of Samedan (Switzerland). International Journal of Bilingual Education and Bilingualism, 4, 38-49.

[9] Cenoz, J., Hufeisen, B. and Jessner, U. (2001). Cross-linguistic influence in third language acquisition. Clevedon: Multilingual Matters.

[10] Croft, W. (1990). Typology and universals. Cambridge: Cambridge University Press.

[11] Cummins, J. (2001). Negotiating identities: Education for empowerment in a diverse society (2nd ed.). Los Angeles: California Association for Bilingual Education.

[12] Dagenais, D., \& Day, E. (1998). Classroom language experiences of trilingual children in French immersion. The Canadian Modern Language Review, 54(3), 376-393.

[13] De Angelis, G. (2007). Third or additional language acquisition (Vol.24). Clevedon: Multilingual Matters.

[14] Dewaele, J.M. (2001). Activation or inhibition? The interaction of L1, L2 and L3 on the language mode continuum. In J. Cenoz, B. Hufeisen \& U. Jessner (Eds.), Cross-linguistic influence in third language acquisition (pp. 69-89). Clevedon: Multilingual Matters.

[15] Edwards, J. (1994). Multilingualism. London and New York: Routledge.

[16] Fleischhacker, H. (2001). Cluster dependent epenthesis asymmetries. UCLA Working papers in linguistics, 7 (5), 71-116.

[17] Flynn, S., Foley, C., \& Vinnitskaya, I. (2004). The cumulative-enhancement model for language acquisition: Comparing adults' and children's patterns of development in first, secondand third language acquisition of relative clauses. International Journal of Multilingualism, 1(1), 3-16.

[18] Jabbari, A. A. (2012). The adaptation of english initial clusters by persian learners. The Journal of Teaching Language Skills, 3(4), 59-76.

[19] Kellerman, E. (1983). Now you see it, now you don't. In S. Gass \& L. Selinker (Eds.), Language transfer in language learning (pp. 112-134). Rowley: Newbury House.

[20] Kramsch, C. (2006). The multilingual subject. International Journal of Applied Linguistics, 16(1), 97110.

[21] Leung, Y. K. I. (2005). L2 vs. L3 initial state: A comparative study of the acquisition of French DPs by Vietnamese monolinguals and Cantonese-English bilinguals. Bilingualism: Language and cognition, 8(01), 39-61.

[22] Leung, Y. K. I. (2006). Full transfer vs. partial transfer in L2 and L3 acquisition. In R. Slabakova, S. Montrul, \& P. Prévost (Eds.), Inquiries in linguistic development. In honor of Lydia White (pp. 157-188). Amsterdam: John Benjamins.

[23] Oksaar, E. (1983). Multilingualism and multiculturalism from the linguist's point of view. In T. Husén \& S. Opper (Eds.), Multicultural and multilingual education in immigrant countries (pp. 17-36). Oxford, New York: Pergamon Press.

[24] Pandey, P. (1991). A psycholinguistic study of democratic values in relation to mono-, bi- and trilingualism. Psycho-Lingua, 21, $111-113$.

[25] Rothman, J. (2010). On the typological economy of syntactic transfer: Word order and high/low attachment preference in relative clause interpretations in L3 Brazilian Portuguese. International Review of Applied Linguistics in Language Teaching, 48(2-3), 245-275.

[26] Rothman, J., \& Cabrelli Amaro, J. (2010). What variables condition syntactic transfer? A look at the L3 initial state. Second Language Research, 26(2), 189-218.

[27] Prince, A., \& Smolensky, P. (1991).Notes on Connectionism and Harmony Theory in linguistics. Report no. CU-CS-533-91: Department of Computer Science, University of Colorado, Boulder.

[28] Vildomec, V. (1963). Multilingualism:General linguistics and psychology of speech. Leiden: Sijthoff.

[29] Weinreich, U. (1953). Languages in contact. The Hague: Mouton.

[30] Williams, S., \& Hammarberg, B. (1998). Language switches in L3 production: Implications for a polyglot speaking model. Applied linguistics, 19(3), 295-333. 
AppendicesAppendix A. Production Test

\begin{tabular}{|l|l|l|l|}
\hline Sprat & Splénite & Springbok & Structure \\
\hline Strobile & Stratus & Splénique & Stratégie \\
\hline Strie & Splenius & Priver & Prison \\
\hline Plat & Plateau & Stock & Stimuler \\
\hline Stigmata & Spectre & Tranche & Tragédie \\
\hline Prunier & Blanche & Blasé & Snober \\
\hline
\end{tabular}

Appendix B. The Oral Judgment Test

Please listen to the voice and read the following words and choose the correct pronunciation:

1) a. [seperat]b. [esprat]c. [sprat]d. [esperat]

2) a. [pRive] , [pRizo]b. [peRive] , [peRizo]c. [pRive] , [perizo] d. [perive] , [pRizo]

3) a. [parle] , [paro] b. [parle] , [paro]c. [parler], [parol] d. [parler], [parol]

4) a. [splãdid]b. [sepelãdid]c. [esplãdid] d. [espelãdid]

5) a. [espRinbok]b. [espeRinbok] c. [spRinbsk] d. [sepeRinbsk]

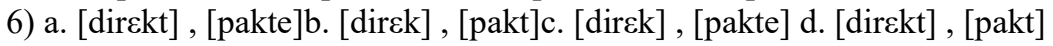

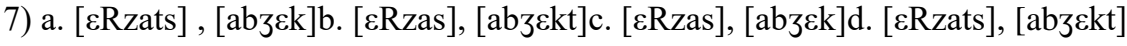

8) a. [pela], [pelato]b. [pla] , [pelato]c. [pela] , [plato]d. [pla], [plato]

9) a. [stRyktyR]b. [seteRyktyR]c. [estRyktyR]d. [esteRyktyR]

10) a. [klape] , [kelak]b. [kelape] , [kelak]c. [klape], [klak] d. [kelape], [klak]

11)a. [selekt] , [selest]b. [selekt], [seles]c. [selek], [selest]d. [selek], [seles]

12) a. [avwaR], [ado]b. [avwaR], [ados]c. [avwaR] , [ado]d. [avwa] , [ados]
13) a. [seteRatys]
b. [stRatys]
c. [estRatys]
d. [esteRatys]

14) a. [deRamatik], [deRy]b. [dRamatik], [dRy]c. [deRamatik], [dRy] d. [dRamatik], [deRy]

15) a. [sepelenik]b. [esplenik] c. [espelenik]d. [splenik]

16) a. [bajl] , [bs]b. [bajl] , [bs]c. [baj] , [be]d. [baj] , [bei]

17) a. [stok] , [stimyle]b. [estok] , [stimyle] c. [stok] , [estimyle]d. [estok] , [estimyle]
18) a. [estRatezi]
b. [stRatezi]
c. [esteRatezi]
d. [seteRatezi]

19)a. [tRãf] , [teRazedi]b. [tRã $\}]$, [tRazedi]c. [teRã ]] , [tRazedi]d. [teRã $]$, [teRazedi]

20) a. [estRi]b. [esteRi]c. [seteRi]d. [stRi]

21) a. [etyde] , [eRydi]b. [etyd] , [eRydit]c. [etyde] , [eRydi]d. [etyd] , [eRydi]
22) a. [splin]
b. [esplin]
c. [espelin]
d. [sepelin]

23) a. [pRynje] , [pRyRt]b. [peRynje], [pRyRt] c. [peRynje] , [peRyRt] d. [pRynje], [peRyRt]

24) a. [snobe], [esmalt]b. [esnobe], [esmalt]c. [esnobe], [smalt] d. [snobe], [smalt]
25) a. [estRobil]
b. [stRobil]
c. [seteRobil]
d. [esteRobil]

26) a. [belãf], [belaze]b. [blãf], [belaze] c. [belãf], [blaze]

d. [blã ]], [blaze]

27) a. [kurt] , [ku]b. [kur] , [ku]c. [kur] , [kup]d. [kurt] , [kup]

28) a. [abri] , [ãmbR]b. [abri] , [ãbR]c. [abi] , [ãbR]d. [abri] , [ãmbR]

29) a. [stigmat] , [ espektR]b. [estigmat] , [spketR]c. [stigmat] , [spektR]

, [espketR]

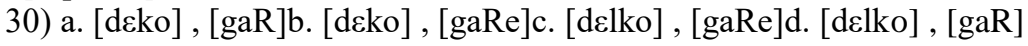

d. [estigmat] 